\title{
LOW FIELD MAGNETOMETER SENSOR OF HIGH STABILITY
}

\author{
By D. I. GORDON and R. H. LUNDSTEN ( $\left.{ }^{\mathbf{1}}\right)$, \\ U.S. Naval Ordnance Laboratory, Silver Spring, Maryland (U.S.A.).
}

\begin{abstract}
Résumé. - Un nouveau détecteur magnétométrique au type "fluxgate ", qui est très stable au passage du temps et au changement de la température, était développé pour l'exploration de l'espace. En accord avec le circuit électronique développé à NASA Ames Research Center, le détecteur n'indique que 0,1 gamma au maximum, quand il reste dans un champ magnétique de zéro. Cette indication à champ-zéro fluctue moins de $\pm 0,1$ gamma dans une période de 24 heures, à la température constante. Aussi, quand la température du détecteur change entre $-30^{\circ} \mathrm{C}$ et $+60^{\circ} \mathrm{C}$, l'indication change moins de 0,4 gamma. Le bruit, à la température de la chambre, est inférieur de 0,2 gamma (amplitude à l'amplitude) à la bande des fréquences entre 0 et $10 \mathrm{~Hz}$. Cette performance du magnétomètre était mesurée en plaçant le détecteur dans un blindage à superconducteur qui est au Naval Ordnance Laboratory. A l'intérieur du blindage, le champ magnétique statique est inférieur à 0,1 gamma, les gradients statiques sont moins de 0,1 gamma/inch, et l'atténuation des champs magnétiques changeants (au passage du temps) est $10^{6}$.
\end{abstract}

Abstract. - Highly stable with time and temperature, a new fluxgate magnetometer sensor was developed for space exploration. In conjunction with the electronic circuitry developed by the NASA Ames Research Center, the sensor-electronics combination shows a zero-field setting below 0.1 gamma, which fluctuates less than \pm 0.1 gamma in a 24-hour period at constant temperature. The zero level also shifts less than 0.4 gamma when the temperature of the sensor is shifted from -30 to $+60{ }^{\circ} \mathrm{C}$. Room temperature noise is less than 0.2 gamma peak-to-peak in the 0 to $10 \mathrm{~Hz}$ frequency band. This magnetometer performance was measured by placing the sensor in a superconducting shield at the Naval Ordnance Laboratory. Within the superconducting shield, the static magnetic field is less than 0.1 gamma, the static gradients are less than 0.1 gamma per inch, and the attenuation to time-varying fields is $10^{6}$.

Introduction. - Measurement of low magnetic fields in space requires an instrument whose zerofield reading is highly stable with time passage and with temperature variations. In particular, recent space experiments have demonstrated the need for a magnetometer which has the following characteristics :

- Resolution : \pm 0.2 gamma.

- Long-term stability of zero-field reading : Less than \pm 0.2 gamma in 24 hours at constant temperature.

- Operating temperature : $-30^{\circ} \mathrm{C}$ to $+65^{\circ} \mathrm{C}$.

- Temperature sensitivity : Less than \pm 0.2 gamma change in zero-field reading due to temperature change.

- Average value of zero-field reading : Less than 0.3 gamma.

This paper describes a highly stable fluxgate magnetometer sensor whose performance, when coupled with the electronics [1] developed by the NASA Ames Research Center, more than meets these requirements. The magnetic core of this sensor is toroidal. It is made of 6-81 Mo Permalloy tape (0.0005 inch thick) spirally wound on a ring-shaped non-magnetic bobbin.

To determine the performance of this sensor in a constant, low-field region, where temperature could be accurately controlled and varied as required, use was made of a superconducting shield at the Naval Ordnance Laboratory (NOL). Within the test region

(1) Visiting Scientist for the 1968-69 academic year at the Technion Israel Institute of Technology, Haifa, and at the Weizmann Institute of Science, Rehovoth, Israel. of this shield, the maximum static magnetic field was less than 0.1 gamma and the maximum gradient of this field was less than 0.1 gamma/inch. Furthermore, external a-c fields were attenuated by a factor of $10^{6}$. Sensor performance data were also checked in a conventional flux tank at Ames [2].

At the present stage of development, NOL ring-core fluxgate sensors can be made with a zero-field reading whose average value is less than 0.1 gamma, and which changes less than \pm 0.1 gamma in 24 hours at constant temperature, or with temperature variations in the range of -30 to $+60^{\circ} \mathrm{C}$. Noise at room temperature is less than 0.2 gamma peak to peak in the 0 to $10 \mathrm{~Hz}$ frequency band.

Sensor construction. - The use of a toroidal magnetic core (i.e., a closed magnetic core) in place of two straight, parallel open-cores in the sensor of a fluxgate magnetometer was first demonstrated by Geyger [3]. See figure 1. He also pointed out two

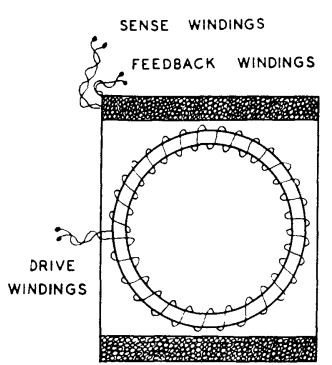

a

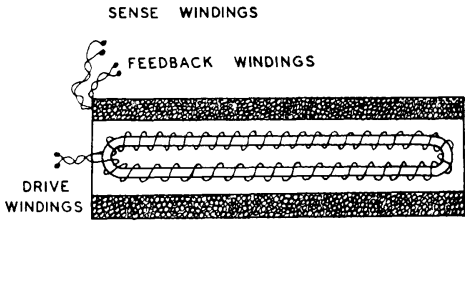

b
FIG. 1. - Two closed-core fluxgate sensors : a) Ring-core configuration ; b) Racetrack configuration. 
primary advantages of closed-core sensors over opencore sensors, namely [1] lower driving power and [2] extremely high resistance to permanent magnetization due to high field exposure.

Gordon et al. [4, 5, 6] analyzed the operation of the ring-core magnetometer in the gamma-level region using second-harmonic detection circuitry and found a way to construct ring-core sensors with resolution of better than 0.1 gamma and with stability better than \pm 0.1 gamma. Among the factors contributing to this performance are :

1) Magnetic core material, 6-81 Mo Permalloy, with very low magnetostriction;

2) Non-magnetic bobbin material, Inconel $X-750$;

3) Winding of the Permalloy tape on the ring-shaped Inconel bobbin with uniform strains throughout the tape;

4) High temperature annealing of the tape-bobbin assembly to relieve winding strain and to provide suitable magnetic properties to the tape;

5) Matching of the temperature coefficient of expansion of the bobbin material (Inconel) to that of the core material (Permalloy);

6) A sturdy coil form for the sense (or pickup) and feedback windings of the sensor. Non-magnetic glassfilled epoxy was used as the material for this rectangular solenoid-shaped coil form;

7) Rotatability of the ring-core within the sense coil to optimize the initial setting of the zero-field reading.

Factors 1), 3), 4), 5) and 6) contribute to stability with time and temperature by minimizing the effects of dimensional changes from whatever causes (e.g., temperature change, shock, vibration, ageing) on the magnetometric performance of the sensor. The use of non-magnetic materials for the core bobbin and for the coil form, factors 2) and 6 ) respectively, reduces the zero-field reading to a low level, which can then be further reduced by rotating the ring-shaped core within the rectangular-solenoid sense coil until a minimum value of zero-field setting is achieved. Additional details on the sensor construction are given in reference [6].

Sensor tests in superconducting shield. - The superconducting shield at NOL developed by Brown [7] contains a dewar-type thermal shield (open at one end) within the superconducting enclosure, thus permitting the sensor under test to be at controlled temperatures in the range of $-60^{\circ} \mathrm{C}$ to $+60^{\circ} \mathrm{C}$, while within the superconducting shield environment. The working volume within the thermal shield has a 1.75 inch diameter and a usable length of 3 inches. Typical values of static field and gradient, and attenuation to time-varying fields within this volume are :

- Field : Less than 0.1 gamma.

- Gradient : Less than 0.1 gamma/inch.

- Attenuation to time-varying fields : transverse, $5 \times 10^{5}$ at bottom to $10^{4}$ at 3 inches from bottom; axial, $2 \times 10^{7}$ at bottom to $2 \times 10^{5}$ at 3 inches from bottom.

Temperature is controlled to $\pm 0.25^{\circ} \mathrm{G}$ by means of a system which automatically senses and heats a supply of air or evaporating liquid nitrogen which is supplied to the test volume. Details are shown in reference [6].

Since the superconducting shield insures that the magnetic field environment seen by the sensor under test is extremely stable, the stability of the sensor is evaluated by observing the output reading as a function of time and temperature. A typical test cycle consists of one hour at room temperature, heating to $+60^{\circ} \mathrm{C}$ at a rate of $1^{\circ} \mathrm{C} / \mathrm{mn}$, one hour at $+60^{\circ} \mathrm{C}$, cooling to room temperature, one-half hour at room temperature, cooling to $-30^{\circ} \mathrm{C}$ at $2^{\circ} \mathrm{C} / \mathrm{mn}$, one hour at $-30^{\circ} \mathrm{C}$, heating to room temperature at $2{ }^{\circ} \mathrm{C} / \mathrm{mn}$, and finally one hour at room temperature.

Sensor performance. - Typical sensor stability performance curves are shown in figure 2 . Curve (a)

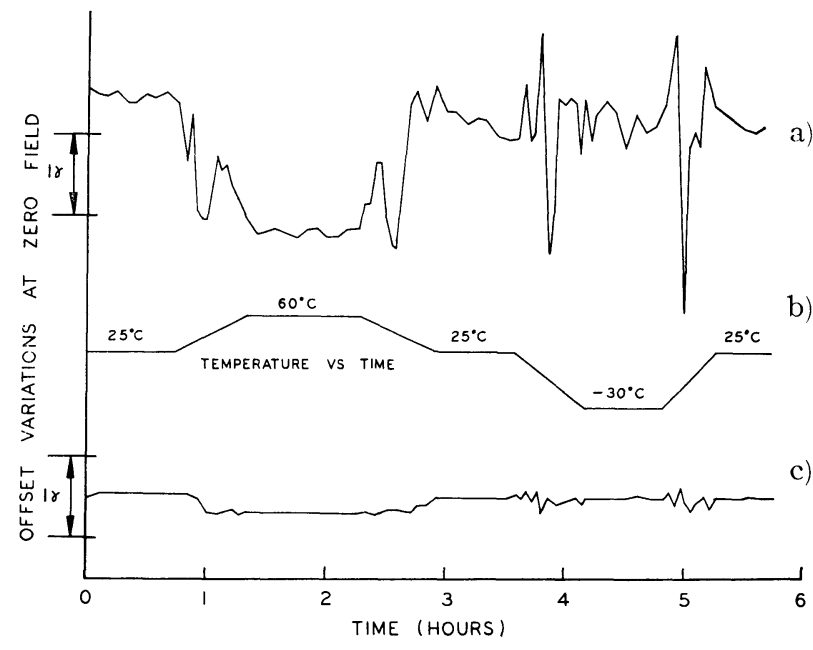

FIG. 2. - Typical sensor stability performance curves a) Zero-field reading (offset) versus time during temperature cycle for earlier sensor ; b) Temperature versus time test cycle; c) Zero-field reading (offset) versus time during temperature cycle for NOL stable ringcore sensor.

is typical of sensor stability behavior before the availability of the NOL stable ring-core sensor. Curve (c) is a sample of NOL ring-core sensor stability. Analysis of this and other curves shows that the zero-field reading fluctuates less than \pm 0.1 gamma at constant temperature, fluctuates less than \pm 0.15 gamma during rapid temperature changes, shifts less than 0.4 gamma when the temperature is shifted from $-30^{\circ} \mathrm{C}$ to $+60^{\circ} \mathrm{C}$, and shows a permanent change of less than 0.1 gamma as a result of the temperature cycling treatment. Room temperature noise in the $0-10 \mathrm{~Hz}$ frequency band ranges typically from 0.1 to 0.2 gamma peak to peak.

Acknowledgement. - The efforts of the following are gratefully acknowledged : J. F. Scarzello and R. A. Chiarodo for ably assisting in fabricating and evaluating the sensors and for helping solve many of the difficult engineering and design problems; H. H. Helms Jr for supplying Permalloy core material and heat treating the sensor cores; R. E. Brown for developing the superconducting shield system and for advice and aid in its utilization; and the National Aeronautics and Space Agency for funding this project. 


\section{REFERENCES}

[1] Kerwin (W. T.), Munoz (R. M.) et Prucha (M. J.), "An Improved Magnetometer for Deep Space Use ", presented at the I.E.E.E./A.I.A.A. Nat'1 Aerospace Electronics Conference, Dayton, Ohio, 1964.

[2] LinloR (W. I.), Munoz (R. M.) et Prucha (M. J.), "Stability Measurements of Fluxgate Magnetometers ", presented at the Space Magnetic Exploration and Technology Symposium, Reno, Nevada, 1967.

[3] GFyger (W. A.), "New Type of Fluxgate Magnetometer ", J. Appl. Phys., 1962, 33, 1280-1281.
[4] Gordon (D. I.), Lundsten (R. H.) et ChuaroDO (R. A.), "Factors Affecting the Sensitivity of Gamma-Level Ring-Core Magnetometers ", I.E.E.E. Trans. Magnetics, 1965, MAG-1, 330-337.

[5] Gordon (D. I.), LundSTEN (R. H.) et CHIARoDO (R. A.), "Demagnetization Effect in ClosedCore Magnetometers ", I.E.E.E. Trans. Magnetics, 1966, MAG-2, 773.

[6] Gordon (D. I.), Lundsten (R. H.), Chiarodo (R. A.) et HELMS (H. H.), "A Fluxgate Sensor of High Stability for Low Field Magnetometry ", I.E.E.E. Trans. Magnetics, 1968, MAG-4, 397-401.

[7] Brown (R. E.), " Device for Producing very Low Magnetic Fields ", Rev. Sci. In.st., 1969, 39, 547-550. 